\title{
The Relationship Between DNA Replication and the Induction of Sporulation in Bacillus subtilis
}

\author{
By G. DUNN, P. JEFFS, N. H. MANN, * D. M. TORGERSEN \\ AND M. YOUNG $\dagger$ \\ Microbiology Unit, Department of Biochemistry, South Parks Road, Oxford OX13QU
}

(Received 13 March 1978; revised 14 May 1978)

\begin{abstract}
6-( $p$-Hydroxyphenylazo)uracil (HPUra), which is thought to be a specific inhibitor of DNA replication in many Gram-positive bacteria, has been used to investigate the relationship between DNA replication and the induction of sporulation in Bacillus subtilis. Gene frequency analysis of samples removed from sporulating cultures indicates that sporulating cells terminate their final round of DNA replication at the same time as they escape from the inhibitory effect of HPUra. If the rate of DNA replication during starvation is slowed down by the use of sub-inhibitory concentrations of HPUra, the onset of this escape is delayed. When cells containing only completed chromosomes are transferred from a rich growth medium to a poor sporulation medium they initiate new rounds of DNA replication in the sporulation medium and then subsequently sporulate. The results are consistent with the hypothesis of Mandelstam \& Higgs (1974) that induction of sporulation occurs 15 to 20 min after the initiation of a round of DNA replication.
\end{abstract}

\section{INTRODUCTION}

There is evidence that the initiation of sporulation occurs at a specific point in the cell cycle, provided that the bacteria are being starved of nutrients at the time. Work with thymine-requiring strains of Bacillus subtilis 168 has suggested that termination of the final round of DNA replication is a necessary prerequisite for sporulation (Mandelstam et al., 1971). This conclusion is consistent with the observation that spores contain only completed chromosomes (Oishi et al., 1964). Later work by Mandelstam \& Higgs (1974), who used bacteria synchronized with respect to chromosome replication, pointed to a link between induction of sporulation and a specific stage in the replication of DNA.

The experiments outlined above were carried out using strains of $B$. subtilis that require thymine for growth. These strains rarely sporulate as well as the wild-type (Mandelstam et al., 1971). It has been shown that the timing of DNA replication in thymine auxotrophs differs from that in thymine prototrophs (Ephrati-Elizur \& Borenstein, 1971). It has also been suggested that the spores of some thymine-requiring strains contain partially replicated chromosomes (Ephrati-Elizur \& Borenstein, 1971; Gillin \& Ganesan, 1975). This would account for the abnormally high ratio of origin to terminus markers found in DNA extracted from spores of thymine auxotrophs. An alternative explanation has been proposed by Callister \& Wake (1974) who drew attention to the fact that mutations conferring a thymine requirement were initially obtained in $B$. subtilis strain w23 and then transferred to strain 168 (Farmer \& Rothman, 1965). Since one of the thy mutations (thy $B$ ) is closely linked to the met $B$ gene, which is normally used as a terminus marker for the analysis of

* Present address: Department of Genetics, University of Leeds.

$\dagger$ Present address: Department of Botany and Microbiology, University College of Wales, Aberystwyth. 
DNA, the fact that a segment of the genetic material in this region is non-isogenic with the remainder of the chromosome could reduce the efficiency of transformation for the met $B$ gene. In this way it is possible to account for high values for the ratio of origin to terminus markers in DNA extracted from spores of thymine-requiring strains. Further support for this interpretation came from the finding that the spores of thymine auxotrophs are homogeneous with respect to their DNA content (Callister \& Wake, 1976). This would not be expected if they contained chromosomes in different stages of replication.

In view of these uncertainties about thymine-requiring strains, we decided to investigate the relationship between DNA replication and induction of sporulation in a strain that does not require thymine for growth. In addition, we wanted to use a method which, unlike that of Mandelstam \& Higgs (1974), did not rely on the imposition of synchrony on the cultures before resuspension in the sporulation medium. We have therefore used the drug $6-(p-$ hydroxyphenylazo)uracil (HPUra) to prevent DNA replication after the transfer of wildtype cells to a sporulation medium. This compound, at a suitable concentration (about $10 \mu \mathrm{g} \mathrm{ml}^{-1}$ or higher), causes an almost immediate and complete inhibition of DNA replication in $B$. subtilis and is thought to prevent the action of DNA polymerase III (Brown, 1970, 1971; Love et al., 1976). In view of the results previously obtained with thymine-requiring bacteria, HPUra would be expected to prevent sporulation if it were added early enough. When sporulation is induced by nutrient exhaustion, HPUra does indeed inhibit development if it is added within $2 \mathrm{~h}$ of the time at which growth ceases to be exponential (Leighton et al., 1975; Shibano et al., 1978). Unfortunately, in these experiments it is not possible to ascertain precisely when the stimulus that induces sporulation is given. This difficulty does not arise when a replacement technique is used to obtain sporulation (Sterlini \& Mandelstam, 1969); the time of imposition of nutrient starvation is experimentally determined and therefore precisely known.

In the following experiments, we have investigated the relationship between induction of sporulation and the DNA replication cycle in the wild-type $B$. subtilis. We have determined the time at which sporulation in this strain escapes from the inhibitory effect of HPUra and correlated this escape with the termination of DNA replication as measured by gene frequency analysis. We have also used chloramphenicol-treated cells to test whether initiation of a round of DNA replication can occur after resuspension in the sporulation medium. Most of the cells in a starving culture of the wild-type sporulate, and so if there is a critical point during chromosome replication for the induction of sporulation, there must also be reinitiation of new rounds of DNA replication in the sporulation medium. Earlier experiments using a temperature-sensitive DNA replication mutant, however, suggested that there was no reinitiation in the poor medium (Mandelstam et al., 1971).

\section{METHODS}

Growth and sporulation. Bacillus subtilis $168 \operatorname{trpC2}$ was used throughout. This strain sporulates normally and is referred to as the wild-type. Bacteria were grown at $37^{\circ} \mathrm{C}$ with vigorous aeration and the growth of the cultures was determined by measuring their absorbance at $600 \mathrm{~nm}$. The generation time under these conditions was $40 \mathrm{~min}$. Sporulation was induced by transferring exponentially growing bacteria at an $A_{600}$ of 0.7 $\left(0.25 \mathrm{mg}\right.$ dry $\left.\mathrm{wt} \mathrm{m}^{-1}\right)$ from a rich medium containing hydrolysed casein to a poor (sporulation) medium containing L-glutamate and inorganic ions (Sterlini \& Mandelstam, 1969). Both media were supplemented with $20 \mu \mathrm{g}$ tryptophan $\mathrm{ml}^{-1}$. The time (h) after transfer to the poor medium is indicated by $t_{0}, t_{1}$ etc.

Spore counts. To measure numbers of heat-resistant spores, cultures were heated at $80^{\circ} \mathrm{C}$ for $15 \mathrm{~min}$ and then suitable dilutions were plated on nutrient agar (Difco).

Metabolic inhibitors. Protein synthesis during growth was prevented by adding $50 \mu \mathrm{g}$ chloramphenicol $\mathrm{ml}^{-1}$. DNA replication after resuspension in sporulation medium was stopped by adding $50 \mu \mathrm{g} \mathrm{HPUra} \mathrm{ml}^{-1}$. The latter was a gift from B. Langley of Imperial Chemical Industries Ltd.

DNA estimation. DNA was estimated by the method of Burton (1956).

Marker frequency analysis. The method of Sueoka \& Yoshikawa (1965) was used for marker frequency analysis. DNA was prepared from sporulating bacteria essentially as described by Marmur (1961), except 


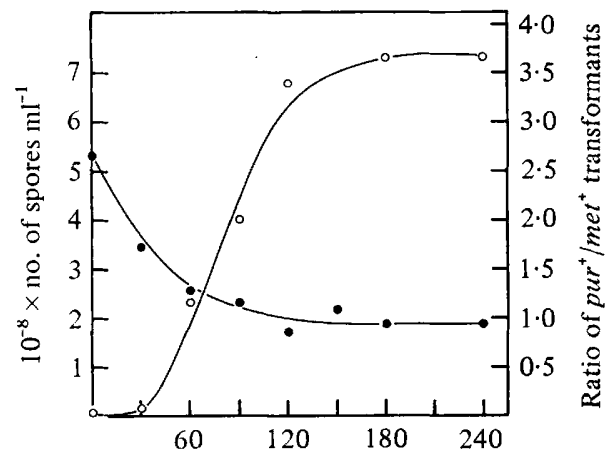

Time (min) of HPUra addition Time ( $\mathrm{min})$ after resuspension

Fig. 1

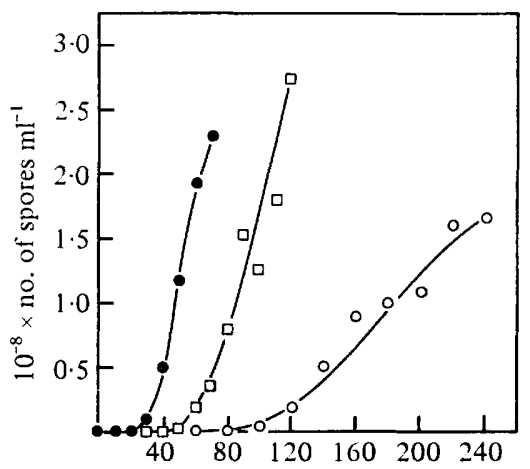

Time of addition of HPUra $\left(50 \mu \mathrm{g} \mathrm{ml}^{-1}\right)$

Fig. 2

Fig. 1. Correlation between escape of sporulation from the effect of HPUra and termination of DNA replication as measured from marker frequency ratios. Bacteria were suspended in sporulation medium and samples of the culture were removed at intervals and treated with HPUra $\left(50 \mu \mathrm{g} \mathrm{ml}^{-1}\right)$ to stop DNA synthesis. Sporulation was measured in these samples and in the control culture at $t_{20}(O)$. The control culture (to which no HPUra had been added) contained $7 \cdot 3 \times 10^{8}$ spores $\mathrm{ml}^{-1}$. For marker frequency analysis, samples were removed from a sporulating culture and DNA was prepared from them. This DNA was used to transform a recipient strain to $\mathrm{pur}^{+}$or to $\mathrm{met}^{+}$(see Methods). The values given for the pur ${ }^{+} / \mathrm{met}^{+}$ratio (e) have been corrected for different transformation efficiencies for the two markers (see Methods).

Fig. 2. Effect of slowing DNA replication during sporulation on subsequent escape from HPUra $\left(50 \mu \mathrm{g} \mathrm{ml}^{-1}\right)$. Bacteria were resuspended in sporulation medium containing no HPUra (o), $0.29 \mu \mathrm{g} \mathrm{HPUra} \mathrm{ml} \mathrm{m}^{-1}(\square)$ or $1.02 \mu \mathrm{g} \mathrm{HPUra} \mathrm{ml}^{-1}(\bigcirc)$. Samples were removed periodically from these cultures and HPUra was added at $50 \mu \mathrm{g} \mathrm{ml}^{-1}$ to stop DNA synthesis. The numbers of spores in all samples were measured at $t_{20}$. There were $2 \cdot 8 \times 10^{8}$ spores $\mathrm{ml}^{-1}$ in the culture to which no HPUra had been added at any time.

that contaminating RNA was not removed. The DNA was used at non-saturating concentrations $(<0 \cdot 2 \mu \mathrm{g}$ DNA ml ${ }^{-1}$ ) to transform the recipient strain, Mu8u5u16 purA16 leu-8 metB5 (from N. Sueoka); transformants to $\mathrm{pur}^{+}$and $\mathrm{met}^{+}$were selected separately. The purAl6 marker is located near the replication origin and the metB5 marker near the terminus; hence, the ratio of $\mathrm{pur}^{+} / \mathrm{met}^{+}$transformants should give an indication of the average number of replicating forks per chromosome. Dormant spores of $B$. subtilis contain completed chromosomes (Oishi et al., 1964) and therefore contain equal numbers of copies of the pur $A$ and $m e t B$ genes. However, in transformation experiments different genes are transferred with different efficiency. In our experiments, DNA extracted from spores [using the method of Takahashi (1968)] gave a ratio of pur $^{+} / \mathrm{met}^{+}$transformants of 0.63 . This value was used as a standard correction factor for all marker ratios obtained to make them comparable to a 'normalized' value of 1.0 for spore DNA (completed chromosomes).

\section{RESULTS}

\section{Effect of HPUra on sporulating cultures}

Bacteria were grown in the rich medium and then transferred to sporulation medium containing HPUra $\left(50 \mu \mathrm{g} \mathrm{ml}^{-1}\right)$. The number of heat-resistant spores at $t_{20}$ was compared with the number of spores produced in a culture not containing the inhibitor. HPUra inhibited sporulation by about $99 \%$, i.e. there were about $5 \times 10^{6}$ spores $\mathrm{ml}^{-1}$ in the culture containing HPUra compared with about $5 \times 10^{8}$ spores $\mathrm{ml}^{-1}$ in the control culture.

The time after resuspension at which DNA replication ceases to be essential for the subsequent sporulation of the wild-type was determined in the following way. Bacteria were transferred from the rich medium to the sporulation medium. At intervals between $t_{0}$ and $t_{4}, 5 \mathrm{ml}$ samples were removed from the main culture and incubated further in the presence of HPUra (final concentration $50 \mu \mathrm{g} \mathrm{ml}^{-1}$ ). The incidence of spores in all samples 
was determined at $t_{20}$. The bacteria began to escape from the effect of HPUra at about 30 min after resuspension (Fig. 1). In 16 experiments the mean value for the time of onset of escape was $35 \mathrm{~min}$, with a standard deviation of $4 \mathrm{~min}$.

\section{Gene frequency analysis of DNA extracted from sporulating cultures}

HPUra has an immediate and specific inhibitory effect on DNA replication (Brown, 1970, 1971). The experiments described above therefore determined the time at which sporulation became independent of DNA replication. Since spores contain completed chromosomes (Oishi et al., 1964), one would expect this time to correspond to the time when the final round of DNA replication is terminated. To check that this was indeed the case, DNA was prepared from samples of bacteria taken from a sporulating culture and subjected to marker frequency analysis (see Methods). As the final rounds of DNA replication in the sporulating culture terminated, one would expect the ratio of the number of pur $^{+}$transformants to the number of $\mathrm{met}^{+}$transformants to decrease from that characteristic of growing cells to that characteristic of spores, as was actually observed (Fig. 1). The $\mathrm{pur}^{+} / \mathrm{met}^{+}$ratio fell from 2.6 at $t_{0}$ to 1.0 at about $t_{2}$. At this time there was complete escape from inhibition of spore formation by HPUra.

\section{Effect of sub-inhibitory concentrations of HPUra on the rate of termination of DNA replication during sporulation}

If the rate of DNA replication in a resuspended culture were reduced, one would expect that the time of chromosome termination, and hence the time of onset of escape from the effect of HPUra, would be delayed. One would also expect the resulting rate of escape to be lower than in the control culture. The rate of DNA replication in starving cultures was reduced by adding sub-inhibitory concentrations of HPUra $\left[0.29\right.$ and $\left.1.02 \mu \mathrm{g} \mathrm{ml}^{-1}\right]$ at the time of resuspension [low concentrations of HPUra have been shown to slow down the rate of DNA replication in B. subtilis in vivo (Anderson \& Ganesan, 1976)]. The time of escape was then determined as before using a high concentration of HPUra $\left(50 \mu \mathrm{g} \mathrm{ml}^{-1}\right)$. Using $0.29 \mu \mathrm{g} \mathrm{ml}^{-1}$, the escape was delayed by about $30 \mathrm{~min}$ (Fig. 2). When the sub-inhibitory dose was increased to $1.02 \mu \mathrm{g} \mathrm{ml}^{-1}$, the onset of escape was delayed longer and the slope of the curve was lower.

\section{$D N A$ replication during sporulation after preincubation with chloramphenicol in the growth medium}

Earlier experiments using a temperature-sensitive DNA replication mutant suggested that when chromosome completion had occurred in a rich medium there was no reinitiation in the poor medium (Mandelstam et al., 1971). To test whether this was also the case with the wild-type, chloramphenicol was added to a growing culture $\left(A_{600}\right.$ about 0.5$)$. The drug was removed $1 \mathrm{~h}$ later when the bacteria were washed and resuspended in sporulation medium. This treatment with chloramphenicol allows the completion of all existing rounds of DNA replication in the growth medium, but prevents the initiation of any new rounds (Maaløe \& Hanawalt, 1961 ; Yoshikawa, 1965). The cells should all have contained completed chromosomes at the time of resuspension in the sporulation medium. After an initial lag of about $40 \mathrm{~min}$ in the sporulation medium, there was DNA accumulation equivalent to about one round of DNA replication (Fig. 3). However, the chloramphenicol treatment caused marked asynchrony and this accumulation of DNA was spread over a period of 4 to $5 \mathrm{~h}$. It is therefore difficult to draw any conclusions concerning the timing of DNA replication in this sporulating culture. That this replication was a necessary prerequisite for sporulation is shown by the fact that sporulation was still prevented by HPUra $\left(50 \mu \mathrm{g} \mathrm{m}^{-1}\right)$. Escape from HPUra was very asynchronous, but was consistent with the observed accumulation of DNA (Fig. 3). In spite of the elongated time scale it is apparent that initiation of new rounds of DNA replication did occur in the sporulation medium. 


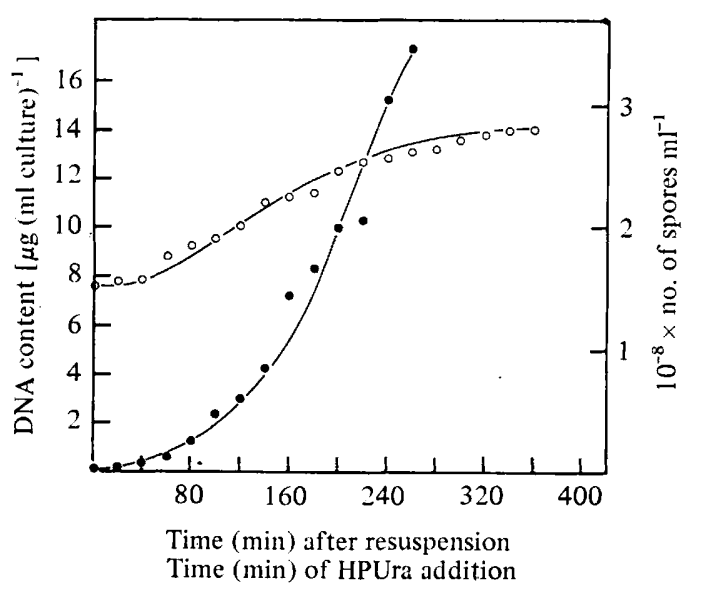

Fig. 3. Reinitiation of DNA synthesis and escape from HPUra in cultures preincubated with chloramphenicol in the growth medium. After the bacteria had grown in rich medium to an $A_{600}$ of 0.5 , chloramphenicol was added and the culture was incubated for $1 \mathrm{~h}$ to allow completion of chromosomes. The bacteria were then washed and resuspended in sporulation medium, and the DNA content of the culture was monitored $(O)$. Samples were also removed from the culture at intervals and treated with HPUra $\left(50 \mu \mathrm{g} \mathrm{ml}^{-1}\right)$ to determine the escape time (O). The numbers of spores produced in these samples were measured at $t_{20}$. There were $3.75 \times 10^{8}$ spores ml-1 in the control culture to which no HPUra had been added.

\section{DISCUSSION}

These experiments show that the amount and rate of sporulation in starving cultures depend on DNA replication. The results confirm the conclusion of Mandelstam et al. (1971) that DNA synthesis in the sporulation medium is a necessary prerequisite for sporulation. The minimum period of DNA synthesis required appears to be about $35 \mathrm{~min}$ (Fig. 1). The results also confirm the observations of Leighton et al. (1975) and of Shibano et al. (1978), who found that HPUra inhibited sporulation when it was induced by nutrient exhaustion.

HPUra has an immediate and specific inhibitory effect on DNA replication in B. subtilis (Brown, 1970, 1971). Our first experiments therefore determined the time at which sporulation becomes independent of DNA replication. Marker frequency analysis indicates that this time can be equated with the time when DNA replication is terminated (Fig. 1). If this is indeed the case, one can conclude from Fig. 1 that the first bacteria to sporulate finished their DNA synthesis about $35 \mathrm{~min}$ after the time of resuspension. The value of the chromosome replication time $(C)$ can be calculated from the marker ratio during growth and the generation time $(\tau)$ using the following relationship (taken from Ephrati-Elizur \& Borenstein, 1971):

$$
\text { Marker ratio }=2^{c / \tau}
$$

For a marker ratio of 2.6 (Fig. 1) and a generation time of $40 \mathrm{~min}$ (see Methods), the value of $C$ is $55 \mathrm{~min}$. This is in agreement with the value of $53 \mathrm{~min}$ obtained by Ephrati-Elizur \& Borenstein (1971). Since the bacteria escaped from the effect of HPUra $35 \mathrm{~min}$ after resuspension, they must already have begun their final round of DNA replication at the time when they were transferred to the sporulation medium. At $t_{0}$ these bacteria were probably about $20 \mathrm{~min}$ into their final round.

The experiments with sub-inhibitory concentrations of HPUra were carried out to test the conclusion that the subsequent escape from a high concentration of HPUra depended on the duration of chromosome replication. If this were so, and if the rate at which chromosomes replicate were to be reduced, one would expect that the onset of escape from HPUra would be delayed and that the subsequent rate of escape would be reduced. This, in fact, was 
observed (Fig. 2). The onset of escape could be postponed to $100 \mathrm{~min}$ after resuspension and the rate of escape reduced to about $25 \%$ of the control value.

The above results are consistent with the assumption that there is a critical time for induction of sporulation and that it occurs about $20 \mathrm{~min}$ after chromosome replication is initiated - Mandelstam \& Higgs (1974) obtained a value of $15 \mathrm{~min}$ in their experiments. Cells in which the critical point has been passed at the time of resuspension are presumed to be unable to sporulate without undergoing another complete round of replication. This category must include a considerable proportion of the cells in the culture because exponentially growing cells contain chromosomes at all stages of replication. If we apply the model for the bacterial cell cycle developed by Cooper \& Helmstetter (1968) to explain the growth of $E$. coli $\mathrm{B} / \mathrm{r}$ to exponentially growing cells of $B$. subtilis 168 with a generation time of about $40 \mathrm{~min}$ (growth on hydrolysed casein at $37^{\circ} \mathrm{C}$ ), then the following can be deduced. Since $C$ is about $55 \mathrm{~min}$ (see earlier), all those cells containing chromosomes in which the terminal $15 \mathrm{~min}$ segment is being replicated will also have reinitiated another round of replication (dichotomous replication) and the replication forks will be within the region that lies before the proposed critical 20 min point. Using the age distribution theorem of Sueoka \& Yoshikawa (1965), it can be shown that about $34 \%$ of the cells in the culture will contain chromosomes undergoing a single round of replication with the replication fork traversing the region between 20 and $40 \mathrm{~min}$. These cells are presumed to be unable to sporulate unless a new round of replication can be initiated in the sporulation medium. Should these cells fail to reinitiate a new round of replication the expected increment of DNA after resuspension would be about $54 \%$. Alternatively, if they do undergo a further round of DNA replication an increment of $106 \%$ would be expected. These values are within the range found experimentally (Mandelstam et al., 1971). Because of the day-to-day variation in the increment in DNA observed and also in the percentage of cells that ultimately contain spores it is difficult to estimate precisely how many sporulating cells have reinitiated new rounds of DNA replication in the sporulation medium.

The hypothesis that a proportion of the cells do initiate a new round of DNA replication in the sporulation medium is consistent with the late escape (60 to $120 \mathrm{~min}$, Fig. 1) of many cells from HPUra. It would also account for the fact that the origin:terminus marker ratio does not fall to unity until about $t_{2}$ (Fig. 1). It is apparently contradicted by the earlier finding that if chromosome replication in a temperature-sensitive mutant is completed in the rich medium, new rounds are not subsequently initiated in the poor medium (Mandelstam et al., 1971; Mandelstam \& Higgs, 1974). The experiment with chloramphenicol was done to determine whether this is generally true or whether it is peculiar to the temperaturesensitive mutant. The values for DNA content (Fig. 3) show that net synthesis of DNA occurs in the poor medium, albeit after a lag of about $40 \mathrm{~min}$. Because of the marked asynchrony induced by the chloramphenicol treatment, the correlation between the observed DNA accumulation and escape from HPUra is qualitative rather than quantitative. Nevertheless, the experiment does show that reinitiation of DNA replication can occur in the poor medium. This conclusion explains why there can be both a critical point for induction of sporulation in the DNA replication cycle and also sporulation in $80 \%$ or more of the cells finally present in a resuspended culture.

We are grateful to Professor $\mathbf{J}$. Mandelstam for advice and criticism. This work was supported by the Science Research Council. One of us (N.H.M.) was a holder of a Guinness Research Fellowship. 


\section{REFERENCES}

Anderson, J. J. \& Ganesan, A. T. (1976). DNA synthesis in vivo in Bacillus subtilis. Journal of Molecular Biology 106, 285-295.

Brown, N. C. (1970). 6-(p-Hydroxyphenylazo)uracil: a selective inhibitor of host DNA replication in phage-infected Bacillus subtilis. Proceedings of the National Academy of Sciences of the United States of America 67, 1454-1461.

Brown, N. C. (1971). Inhibition of bacterial DNA replication by 6 -( $p$-hydroxyphenylazo)-uracil: differential effect on repair and semi-conservative synthesis in Bacillus subtilis. Journal of Molecular Biology 59, 1-16.

Burton, K. (1956). A study of the conditions and mechanism of the diphenylamine reaction for the colorimetric estimation of deoxyribonucleic acid. Biochemical Journal 62, 315-323.

Callister, H. \& WaKe, R. G. (1974). Completed chromosomes in thymine-requiring Bacillus subtilis spores. Journal of Bacteriology 120, 579-582.

Callister, H. \& WAKE, R. G. (1976). Homogeneity in Bacillus subtilis spore DNA content. Journal of Molecular Biology 102, 367-371.

Cooper, S. \& Helmstetter, C. E. (1968). Chromosome replication and the division cycle in Escherichia coli B/r. Journal of Molecular Biology 31, 519-540.

Ephrati-Elizur, E. \& Borenstein, S. (1971). Velocity of chromosome replication in thyminerequiring and independent strains of Bacillus subtilis. Journal of Bacteriology 106, 58-64.

FARMer, J. L. \& Rothman, F. (1965). A transformable thymine-requiring mutant of Bacillus subtilis. Journal of Bacteriology 89, 262-263.

Gillin, F. D. \& Ganesan, A. T. (1975). Control of chromosome replication in thymine-requiring strains of Bacillus subtilis. Journal of Bacteriology 123, 1055-1067.

Leighton, T., Khachatourians, G. \& Brown, N. (1975). The role of semiconservative DNA replication in bacterial cell development. In $I C N-$ UCLA Symposium of Molecular and Cellular Biology III. DNA Synthesis and its Regulation, pp. 677-687. Edited by M. Goulian, P. Hanawalt and C. F. Fox. Menlo Park, California: Benjamin.

Love, E., D'Ambrosio, K. J., Brown, N. C. \& DÚBNAU, D. (1976). Mapping of gene specifying DNA-polymerase 3 of Bacillus subtilis. Molecular and General Genetics 144, 313-321.

MaAløe, O. \& Hanawalt, P. C. (1961). Thymine deficiency and the normal DNA replication cycle I. Journal of Molecular Biology 3, 144-155.

Mandelstam, J. \& Higgs, S. A. (1974). Induction of sporulation during synchronized chromosome replication in Bacillus subtilis. Journal of Bacterio$\log y$ 120, 38-42.

Mandelstam, J., Sterlini, J. M. \& Kay, D. (1971). Sporulation of Bacillus subtilis. Effect of medium on the form of chromosome replication and on initiation of sporulation in Bacillus subtilis. Biochemical Journal 125, 635-641.

MARMUR, J. (1961). A procedure for the isolation of deoxyribonucleic acid from microorganisms. Journal of Molecular Biology 3, 208-218.

OISHI, M., Yoshikawa, H. \& SueOKA, N. (1964). Synchronous and dichotomous replications of the Bacillus subtilis chromosome during spore germination. Nature, London 204, 1069-1073.

Shibano, Y., Tamura, K., Honjo, M. \& Komano, T. (1978). Effect of 6-(para-hydroxyphenylazo)uracil on sporulation in Bacillus subtilis. Agricultural and Biological Chemistry 42, 187-189.

Sterlini, J. M. \& Mandelstam, J. (1969). Commitment to sporulation in Bacillus subtilis and its relationship to development of actinomycin resistance. Biochemical Journal 113, 29-37.

Sueoka, N. \& Yoshikawa, H. (1965). The chromosome of Bacillus subtilis. 1. Theory of marker frequency analysis. Genetics 52, 747-757.

TAKAHASHI, I. (1968). The isolation of nucleic acid from bacterial spores. Methods in Enzymology 12B, 99-100.

Yoshikawa, H. (1965). DNA synthesis during germination of Bacillus subtilis spores. Proceedings of the National Academy of Sciences of the United States of America 53, 1476-1483. 